\title{
The implications of different lateral wall thicknesses on surgical access to the maxillary sinus
}

\section{Ee Lian LIM(a) \\ Wei Cheong NGEOW(a) \\ Daniel LIM(a)}

(a) University of Malaya, Faculty of Dentistry, Department of Oral and Maxillofacial

Clinical Sciences, Kuala Lumpur, Malaysia.
Declaration of Interests: The authors certify that they have no commercial or associative interest that represents a conflict of interest in connection with the manuscript.

\section{Corresponding Author:}

Wei Cheong Ngeow

E-mail: ngeowy@um.edu.my

hitps://doi.org/10.1590/1807-3107bor-2017.vol31.0097

Submitted: May 01, 2017

Accepted for publication: Sep 19, 2017

Last revision: Oct 06,2017

\begin{abstract}
The objective of this study was to measure the topographic thickness of the lateral wall of the maxillary sinus in selected Asian populations. Measurements were made on the lateral walls of maxillary sinuses recorded using CBCT in a convenient sample of patients attending an Asian teaching hospital. The points of measurement were the intersections between the axes along the apices of the canine, first premolar, and second premolar and along the mesiobuccal and distobuccal apices of the first and second molars and horizontal planes $10 \mathrm{~mm}, 20 \mathrm{~mm}, 30 \mathrm{~mm}$ and $40 \mathrm{~mm}$ beneath the orbital floor. The CBCT images of 109 patients were reviewed. The mean age of the patients was 33.0 (SD 14.8) years. Almost three quarters $(71.8 \%)$ of the patients were male. The mean bone thickness decreased beginning at the $10-\mathrm{mm}$ level and continuing to $40 \mathrm{~mm}$ below the orbital floor. Few canine regions showed encroachment of the maxillary sinus. The thickness of the buccal wall gradually increased from the canine region (where sinus encroachment of the canine region was present) to the first molar region, after which it decreased to the thickness observed at the canine region. The buccal wall of the maxillary sinus became thicker anteroposteriorly, except in the region of the second molar, and thinner superoinferiorly. These changes will affect the approach used to osteotomize the lateral sinus wall for oral surgery and for the sinus lift procedure.
\end{abstract}

Keywords: Cone-Beam Computed Tomography; Maxillary Sinus; Dental Implants.

\section{Introduction}

The maxillary sinus is an anatomical structure that is relevant to both medicine (otorhinolaryngology) and dentistry. In the past, otorhinolaryngologists routinely gained access to the maxillary sinus via the Caldwell-Luc approach to treat sinusitis by performing maxillary antrostomy. However, with advances in endoscopic surgery, most otorhinolaryngologists prefer to gain access via the nose when performing functional endoscopic sinus surgery involving the removal of small amounts of bone or other material or the removal of infected tissue and/or polyps. Retained roots, small cysts or tumors can also be removed using this approach. Many other types of maxillary sinus surgery that are performed by oral and maxillofacial surgeons, such as the retrieval of retained root tips, the removal of odontogenic cysts and/or tumors, the reduction and fixation of a Le Fort or zygomatic complex bone fracture and 
sinus floor augmentation to support implant insertion, however, may require a different surgical access to the sinus. The retrieval of a retained root can be performed via the extraction socket and the nose, but the presence of a large cyst or tumor associated with a tooth requires access through the buccofacial (lateral) wall of the maxillary sinus. With the popularity of dental implants, dentists now also gain access to the maxillary sinus to augment bone prior to inserting dental implant fixtures. ${ }^{1}$

Dental implant rehabilitation has become a routine approach to the reconstruction of dentition in patients with partial or total loss of teeth. In fact, it is now recognized as the most cost-effective means of restoring missing teeth over a predictable period of time. ${ }^{2}$ However, implant insertion in the posterior maxilla can be complicated by the presence of the maxillary sinus superiorly. The presence of a low-lying maxillary sinus together with reduced alveolar bone height resulting from natural resorption of bone following dental extraction may limit the amount of vertical bone available for implant fixture insertion. Depending on the amount of bone resorption and the degree of maxillary sinus pneumatization, both of which vary among individuals, the remaining amount of bone available can, in fact, become deficient. ${ }^{3,4,5,6}$ To overcome this problem, dentists have resorted to either inserting short implants or performing maxillary sinus augmentation with bone grafting (sinus lift) to increase the amount of bone available to support implant fixtures of normal length. ${ }^{7}$ The latter procedure can be performed via two different approaches, namely, by the creation of a lateral window ${ }^{7,8}$ or by performing an internal sinus lift using an osteotome to elevate the sinus floor. ${ }^{9}$ To perform lateral sinus window osteotomy, dentists must thoroughly understand the buccofacial wall of the maxillary sinus, an anatomical site that is not routinely taught in detail in most dental schools.

When performing a sinus lift via the lateral wall approach, a window is created using a surgical (tungsten carbide or diamond) rotating bur, a piezosurgical tool or specially designed surgical trephines to create an access or a hinge door on the buccofacial maxillary sinus wall; this is then internally rotated to a horizontal position ${ }^{1}$. The mucoperiosteum of the maxillary sinus floor, i.e., the Schneiderian membrane, is carefully elevated to create a space between this membrane and the sinus floor to allow placement of the bone grafting material of choice ${ }^{10}$. The Schneiderian membrane of the buccofacial sinus wall plays an important role in containing the bone graft, unlike in other oral and maxillofacial surgeries in which this membrane may be breached. However, the vulnerability of the Schneiderian membrane to perforation during this procedure means that it must be managed cautiously while considering the thickness of the buccofacial wall of the maxillary sinus. ${ }^{11}$ A few studies have described the topography and thickness of the buccofacial sinus wall, $12,13,14,15,16,17,18,19$ but none of these have involved Southeast Asian populations.

The objective of this study was to measure the topographic thickness of the buccofacial wall of the maxillary sinus in a cross-section of individuals. The results provide critical information that may be applied when performing lateral window procedures for the purpose of sinus floor augmentation or for gaining access to the sinus to remove cysts or tumors.

\section{Methodology}

This study aimed to determine the thickness of the buccofacial wall maxillary sinuses recorded using cone beam computed tomography (CBCT) in a convenient sample of consecutive patients attending the Oral Radiology Unit between 2010 and 2015. This study received the relevant Institutional Board of Study approval from the Faculty of Dentistry [DF OS1522/0090(L)], University of Malaya.

\section{Materials}

The CBCT scans used in this study were recorded using an i-CAT imaging system (Imaging Sciences International, Inc., Hatfield, USA) at the Oral \& Maxillofacial Radiology Division, Faculty of Dentistry, University of Malaya. All patients gave their informed consent to assessment using $\mathrm{CBCT}$ while consulting this division for other dental examinations. In all patients, the scan was medically justified. The patients were made aware that the data from their images would be used for research purposes, and all of them consented to this provision. All of the images were obtained by the same radiographer using a standardized protocol for patient positioning, exposure parameters of 120 $\mathrm{KVp}, 3-7 \mathrm{~mA}$, and $20 \mathrm{sec}$ and image acquisition at a 
voxel size of $0.3 \mathrm{~mm}$. The images were reconstructed from the $\mathrm{CBCT}$ data using proprietary i-CAT image reconstruction software. Patients with (suspected) pathological lesions in the maxillary sinus, Le Fort I or maxillary wall(s) fractures and images of low quality were excluded from this study.

\section{Measurements}

The obtained images were viewed with proprietary software using the multiplanar reconstruction module. All images were assessed under standardized conditions at an examination workstation. Patients' data, scan data, and assigned measurement scores were recorded in a Microsoft Excel 2007 database (version 2007, Microsoft ${ }^{\circledR}$, Redmond, USA). All included scans had a complete set of upper dentition that spanned the right second molar to the left second molar.

Measurements were made on the buccofacial wall of the maxillary sinus from the canine to the second molar. In the multiplanar view, scrolling of the vertical line was performed to the end of the long axis of each of the following teeth: canine (C), first premolar (PM1), second premolar (PM2), the mesiobuccal (MB) and distobuccal (DB) apices of the first molar (M1) and the mesiobuccal and distobuccal apices of the second molar (M2). Four horizontal reference lines were established 10, 20, 30 and $40 \mathrm{~mm}$ inferior to the floor of the orbit; these were designated $\mathrm{H} 10, \mathrm{H} 20, \mathrm{H} 30$ and $\mathrm{H} 40$, respectively. The intersecting points of the vertical and the horizontal lines were the reference site for measuring bone thickness (Figure 1). All measurements were performed using images observed in the coronal plane.

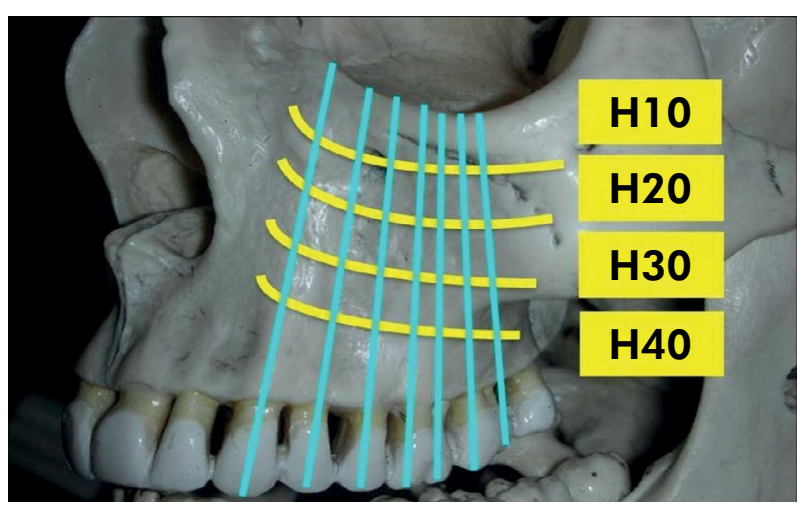

Figure 1. Illustration showing the points of measurement at the buccofacial wall of the maxillary sinus.
The first author performed the measurements twice at an interval of at least 2 weeks to determine intra-observer variability. The reproducibility of the results was tested using the Bland and Altmann test. Mean and standard deviation values were calculated using Microsoft Excel software (version 2007, Microsoft@, Redmond, USA) and SPSS Statistics 12.0 for Windows software (SPSS, v.12.0, IBM, Chicago, USA). The thickness of the buccofacial wall thickness in each group according to gender (male and female groups), ethnicity (Malay, Chinese and Indian), horizontal and vertical location and age was compared using $t$-tests or ANOVA where appropriate. Differences in buccofacial wall thickness in various regions were considered statistically significant at the 5\% probability level.

\section{Results}

The CBCT images of 109 patients were included. Most of the patients were Malay $(n=41 ; 37.6 \%)$, followed by Chinese $(n=37 ; 33.9 \%)$ and Indian $(n=31 ; 28.4 \%)$. The mean age of the patients was 33.0 (SD 14.8) years. Almost three quarters $(71.8 \%$ ) of the patients were male. Males accounted for $70.3 \%$ of the Malay patients, $65.7 \%$ of the Chinese patients and $80.6 \%$ of the Indian patients.

All measuring reference points at the molars and premolars showed the presence of the buccofacial maxillary sinus wall and thus allowed for complete measurements, except in the case of 1 Indian patient for whom the points at the second premolar were missing. However, the sinus wall could not be observed at the canine and first premolar regions. Few canine regions showed the existence of a buccofacial maxillary sinus wall, suggesting that the maxillary sinus does not usually extend to the canine region. Overall, only 43 sites (39.4\%) showed this involvement. This affected $36.6 \%$ of the Malay, $54.1 \%$ of the Chinese and $25.4 \%$ of the Indian patients, suggesting that the maxillary sinus usually extends more anteriorly in Chinese patients than in Malay or Indian patients. Adjacent to the canine, $88(80.7 \%)$ first premolars showed the presence of the buccofacial maxillary sinus wall. This affected $78.0 \%$ of the Malay, $97.3 \%$ of the Chinese and $64.5 \%$ of the Indian patients, similar to the pattern seen in the canine region (Figure 2). 


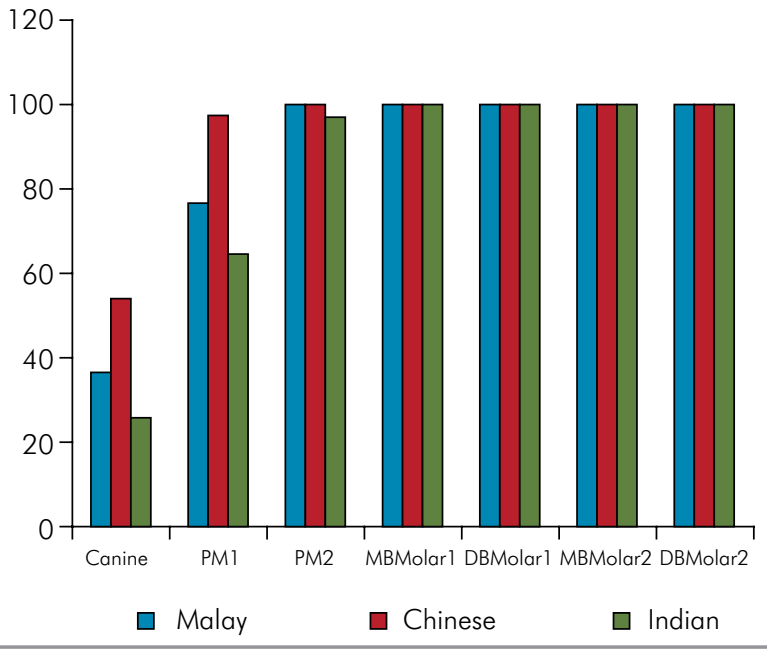

Figure 2. Percentage of sites with the presence (encroachment) of the maxillary sinus, thus enabling measurement of the buccofacial sinus wall to be obtained.
Beginning from the second premolar onward, the buccofacial wall of the maxillary sinus was observed in relationship to all posterior teeth. Measurement of the buccofacial wall thickness was accomplished at all sites that showed maxillary sinus extension; the results are shown in Tables 1 and 2. In all, 3052 measurements were performed on 109 CBCTs. The Bland and Altmann test showed high reproducibility of the data, with $4.32 \%$ difference between the first and second measurements.

In relation to the teeth, the buccal wall thickness gradually increased from the canine to the first molar, after which the thickness decreased to a value similar to that observed at the canine region. The overall mean bone thickness at the canine and the first and second

Table 1. Thickness of bone at different levels in relations to the canine, premolars and first and second molars according to gender.

\begin{tabular}{|c|c|c|c|c|}
\hline \multirow{2}{*}{ Location } & \multicolumn{4}{|c|}{ Thickness of bone at different levels $(\mathrm{mm}) ;(95 \% \mathrm{Cl})$} \\
\hline & $\mathrm{H} 10$ & $\mathrm{H} 2 \mathrm{O}$ & $\mathrm{H} 30$ & $\mathrm{H} 40$ \\
\hline \multirow{2}{*}{ Canine } & $5.05 \pm 2.78$ & $4.09 \pm 1.42$ & $4.05 \pm 1.48$ & \multirow[b]{2}{*}{-} \\
\hline & $(4.20$ to 5.91$)$ & (3.22 to 4.95$)$ & $(-9.29$ to 17.39$)$ & \\
\hline Male & $5.19 \pm 2.56$ & $4.00 \pm 1.62$ & 5.10 & - \\
\hline Female & $4.89 \pm 3.47$ & $4.60 \pm 0.97$ & 3.00 & - \\
\hline \multirow{2}{*}{ First premolar } & $6.15 \pm 4.29$ & $4.84 \pm 2.66$ & $3.92 \pm 1.20$ & $4.07 \pm 1.19$ \\
\hline & $(5.23$ to 7.06$)$ & $(4.21$ to 5.46$)$ & (3.53 to 4.30$)$ & (2.82 to 5.33$)$ \\
\hline Male & $5.93 \pm 4.36$ & $4.75 \pm 2.61$ & $4.06 \pm 1.14$ & $4.07 \pm 1.19$ \\
\hline Female & $6.56 \pm 4.20$ & $5.01 \pm 2.91$ & $3.55 \pm 1.39$ & - \\
\hline \multirow{2}{*}{ Second premolar } & $8.73 \pm 4.35$ & $6.38 \pm 3.76$ & $4.10 \pm 1.50$ & $3.98 \pm 2.14$ \\
\hline & (7.90 to 9.56$)$ & $(5.65$ to 7.11$)$ & (3.77 to 4.43 ) & (2.84 to 5.12$)$ \\
\hline Male & $8.85 \pm 4.72$ & $6.42 \pm 4.02$ & $4.17 \pm 1.57$ & $4.21 \pm 2.19$ \\
\hline Female & $8.55 \pm 3.67$ & $6.34 \pm 3.40$ & $3.93 \pm 1.49$ & $2.40 \pm 0.42$ \\
\hline \multirow{2}{*}{ MB root of the first molar } & $9.09 \pm 3.46$ & $6.20 \pm 2.94$ & $3.41 \pm 1.34$ & $2.37 \pm 1.05$ \\
\hline & (8.43 to 9.75$)$ & (5.64 to 6.76$)$ & (3.10 to 3.72$)$ & (1.62 to 3.12$)$ \\
\hline Male & $9.17 \pm 3.40$ & $6.05 \pm 2.71$ & $3.43 \pm 1.26$ & $2.47 \pm 1.07$ \\
\hline Female & $9.20 \pm 3.85$ & $6.69 \pm 3.67$ & $3.31 \pm 1.60$ & 1.50 \\
\hline \multirow{2}{*}{ DB root of the first molar } & $9.68 \pm 5.03$ & $7.07 \pm 4.67$ & $3.54 \pm 2.62$ & $2.80 \pm 1.42$ \\
\hline & (8.77 to 10.64$)$ & (6.19 to 7.96$)$ & $(2.98$ to 4.11$)$ & (2.15 to 3.45$)$ \\
\hline Male & $9.77 \pm 4.99$ & $7.05 \pm 4.47$ & $3.70 \pm 2.77$ & $2.77 \pm 1.48$ \\
\hline Female & $8.89 \pm 5.27$ & $6.59 \pm 5.03$ & $3.18 \pm 2.46$ & $3.15 \pm 1.06$ \\
\hline \multirow{2}{*}{$M B$ root of the second molar } & $6.01 \pm 4.73$ & $4.27 \pm 4.01$ & $2.72 \pm 2.12$ & $2.40 \pm 1.22$ \\
\hline & (5.12 to 6.91$)$ & (3.51 to 5.03 ) & (2.27 to 3.17$)$ & (1.93 to 2.87 ) \\
\hline Male & $5.99 \pm 4.65$ & $4.42 \pm 4.05$ & $2.83 \pm 2.44$ & $2.44 \pm 1.27$ \\
\hline Female & $5.92 \pm 4.72$ & $4.10 \pm 4.28$ & $2.43 \pm 1.01$ & $1.65 \pm 0.21$ \\
\hline \multirow{2}{*}{ DB root of the second molar } & $3.87 \pm 3.45$ & $3.05 \pm 2.92$ & $2.40 \pm 1.28$ & $2.44 \pm 1.22$ \\
\hline & (3.21 to 4.52 ) & $(2.49$ to 3.60$)$ & (2.13 to 2.67$)$ & (1.95 to 2.94$)$ \\
\hline Male & $4.04 \pm 3.48$ & $3.35 \pm 3.38$ & $2.43 \pm 1.36$ & $2.41 \pm 1.20$ \\
\hline Female & $3.68 \pm 3.70$ & $2.45 \pm 1.43$ & $2.41 \pm 1.40$ & $2.70 \pm 1.87$ \\
\hline Overall & $\begin{array}{c}7.14 \pm 4.66 \mathrm{~mm} \\
(6.70 \text { to } 7.50)\end{array}$ & $\begin{array}{c}5.29 \pm 3.84 \mathrm{~mm} \\
(4.99 \text { to } 5.60)\end{array}$ & $\begin{array}{c}3.28 \pm 1.90 \mathrm{~mm} \\
(3.11 \text { to } 3.45)\end{array}$ & $\begin{array}{c}2.82 \pm 1.52 \mathrm{~mm} \\
(2.53 \text { to } 3.11)\end{array}$ \\
\hline Male & $7.20 \pm 4.70 \mathrm{~mm}$ & $5.34 \pm 3.84 \mathrm{~mm}$ & $3.36 \pm 2.03 \mathrm{~mm}$ & $2.87 \pm 1.57 \mathrm{~mm}$ \\
\hline Female & $6.99 \pm 4.61 \mathrm{~mm}$ & $5.19 \pm 3.93 \mathrm{~mm}$ & $3.07 \pm 1.65 \mathrm{~mm}$ & $2.40 \pm 1.14 \mathrm{~mm}$ \\
\hline
\end{tabular}


Table 2. Thickness of bone at different levels in relation to the canine, premolars and first and second molars according to ethnicity.

\begin{tabular}{|c|c|c|c|c|}
\hline \multirow{2}{*}{ Location } & \multicolumn{4}{|c|}{ Thickness of bone at different levels; $(95 \% \mathrm{Cl})$} \\
\hline & $\mathrm{H} 10$ & $\mathrm{H} 2 \mathrm{O}$ & $\mathrm{H} 30$ & $\mathrm{H} 40$ \\
\hline \multicolumn{5}{|l|}{ Canine } \\
\hline Malay & $\begin{array}{c}5.50 \pm 1.98 \mathrm{~mm} \\
(4.41 \text { to } 6.60)\end{array}$ & $\begin{array}{c}4.35 \pm 1.40 \mathrm{~mm} \\
(2.13 \text { to } 6.58)\end{array}$ & $\begin{array}{l}4.05 \pm 1.48 \mathrm{~mm} \\
(-9.29 \text { to } 17.39)\end{array}$ & - \\
\hline Chinese & $\begin{array}{c}5.21 \pm 3.60 \mathrm{~mm} \\
(3.53 \text { to } 6.90)\end{array}$ & $\begin{array}{c}3.97 \pm 1.50 \mathrm{~mm} \\
(2.81 \text { to } 5.13)\end{array}$ & - & - \\
\hline Indian & $\begin{array}{c}3.80 \pm 0.97 \mathrm{~mm} \\
(2.99 \text { to } 4.61)\end{array}$ & - & - & - \\
\hline \multicolumn{5}{|c|}{ First premolar } \\
\hline Malay & $\begin{array}{c}7.08 \pm 5.26 \mathrm{~mm} \\
(5.18 \text { to } 8.97)\end{array}$ & $\begin{array}{c}4.66 \pm 2.23 \mathrm{~mm} \\
(3.78 \text { to } 5.54)\end{array}$ & $\begin{array}{c}3.73 \pm 1.08 \mathrm{~mm} \\
(3.10 \text { to } 4.35)\end{array}$ & $4.02 \mathrm{~mm}$ \\
\hline Chinese & $\begin{array}{c}6.02 \pm 3.45 \mathrm{~mm} \\
(4.85 \text { to } 7.18)\end{array}$ & $\begin{array}{c}5.48 \pm 3.24 \mathrm{~mm} \\
(4.31 \text { to } 6.64)\end{array}$ & $\begin{array}{c}4.09 \pm 1.26 \mathrm{~mm} \\
(3.55 \text { to } 4.64)\end{array}$ & $\begin{array}{c}4.08 \pm 1.34 \mathrm{~mm} \\
(2.42 \text { to } 5.74)\end{array}$ \\
\hline Indian & $\begin{array}{c}4.90 \pm 3.72 \mathrm{~mm} \\
(3.15 \text { to } 6.64)\end{array}$ & $\begin{array}{c}3.62 \pm 1.12 \mathrm{~mm} \\
(2.95 \text { to } 4.30)\end{array}$ & $\begin{array}{c}3.63 \pm 1.39 \mathrm{~mm} \\
(1.42 \text { to } 5.84)\end{array}$ & - \\
\hline \multicolumn{5}{|c|}{ Second premolar } \\
\hline Malay & $\begin{array}{c}7.85 \pm 3.67 \mathrm{~mm} \\
(6.69 \text { to } 9.01)\end{array}$ & $\begin{array}{c}5.93 \pm 3.31 \mathrm{~mm} \\
(4.89 \text { to } 6.98)\end{array}$ & $\begin{array}{c}3.78 \pm 1.29 \mathrm{~mm} \\
(3.31 \text { to } 4.24)\end{array}$ & $\begin{array}{c}3.92 \pm 2.28 \mathrm{~mm} \\
(1.09 \text { to } 6.75)\end{array}$ \\
\hline Chinese & $\begin{array}{c}10.11 \pm 4.65 \mathrm{~mm} \\
(8.56 \text { to } 11.66)\end{array}$ & $\begin{array}{c}7.08 \pm 3.82 \mathrm{~mm} \\
(5.80 \text { to } 8.35)\end{array}$ & $\begin{array}{c}4.30 \pm 1.78 \mathrm{~mm} \\
(3.66 \text { to } 4.94)\end{array}$ & $\begin{array}{c}3.93 \pm 2.28 \mathrm{~mm} \\
(2.30 \text { to } 5.56)\end{array}$ \\
\hline Indian & $\begin{array}{c}8.22 \pm 4.53 \mathrm{~mm} \\
(6.53 \text { to } 9.91)\end{array}$ & $\begin{array}{c}6.11 \pm 4.31 \mathrm{~mm} \\
(4.37 \text { to } 7.85)\end{array}$ & $\begin{array}{c}4.35 \pm 1.23 \mathrm{~mm} \\
(3.70 \text { to } 5.00)\end{array}$ & $4.80 \mathrm{~mm}$ \\
\hline \multicolumn{5}{|c|}{ MB root of the first molar } \\
\hline Malay & $\begin{array}{c}8.73 \pm 3.35 \mathrm{~mm} \\
(7.67 \text { to } 9.78)\end{array}$ & $\begin{array}{c}6.33 \pm 2.97 \mathrm{~mm} \\
(5.39 \text { to } 7.27)\end{array}$ & $\begin{array}{c}3.63 \pm 1.31 \mathrm{~mm} \\
(3.15 \text { to } 4.12)\end{array}$ & $\begin{array}{c}2.18 \pm 0.49 \mathrm{~mm} \\
(1.41 \text { to } 2.95)\end{array}$ \\
\hline Chinese & $\begin{array}{c}9.80 \pm 3.51 \mathrm{~mm}^{*} \\
(8.63 \text { to } 10.97)\end{array}$ & $\begin{array}{c}6.92 \pm 3.27 \mathrm{~mm} \\
(5.83 \text { to } 8.01)\end{array}$ & $\begin{array}{c}3.17 \pm 1.25 \mathrm{~mm} \\
(2.72 \text { to } 3.62)\end{array}$ & $\begin{array}{c}2.50 \pm 1.34 \mathrm{~mm} \\
(1.10 \text { to } 3.91)\end{array}$ \\
\hline Indian & $\begin{array}{l}8.72 \pm 3.52 \mathrm{~mm} \\
(7.41 \text { to } 10.04)\end{array}$ & $\begin{array}{c}5.14 \pm 2.16 \mathrm{~mm} \\
(4.33 \text { to } 5.95)\end{array}$ & $\begin{array}{c}3.48 \pm 1.64 \mathrm{~mm} \\
(2.49 \text { to } 4.47)\end{array}$ & - \\
\hline \multicolumn{5}{|c|}{ DB root of the first molar } \\
\hline Malay & $\begin{array}{c}9.59 \pm 4.69 \mathrm{~mm} \\
(8.11 \text { to } 11.07)\end{array}$ & $\begin{array}{c}7.41 \pm 4.42 \mathrm{~mm} \\
(6.01 \text { to } 8.81)\end{array}$ & $\begin{array}{c}4.05 \pm 3.24 \mathrm{~mm} \\
(2.92 \text { to } 5.18)\end{array}$ & $\begin{array}{c}3.42 \pm 1.61 \mathrm{~mm} \\
(2.19 \text { to } 4.66)\end{array}$ \\
\hline Chinese & $\begin{array}{c}11.11 \pm 5.70 \mathrm{~mm}^{*} \\
(9.21 \text { to } 13.01)\end{array}$ & $\begin{array}{c}8.15 \pm 5.18 \mathrm{~mm}^{*} \\
(6.43 \text { to } 9.88)\end{array}$ & $\begin{array}{c}3.09 \pm 2.42 \mathrm{~mm} \\
(2.24 \text { to } 3.95)\end{array}$ & $\begin{array}{c}2.18 \pm 1.04 \mathrm{~mm} \\
(1.48 \text { to } 2.88)\end{array}$ \\
\hline Indian & $\begin{array}{c}8.10 \pm 4.20 \mathrm{~mm} \\
(6.56 \text { to } 9.64)\end{array}$ & $\begin{array}{c}5.33 \pm 3.94 \mathrm{~mm} \\
(3.89 \text { to } 6.78)\end{array}$ & $\begin{array}{c}3.42 \pm 1.23 \mathrm{~mm} \\
(2.81 \text { to } 4.03)\end{array}$ & $4.00 \mathrm{~mm}$ \\
\hline \multicolumn{5}{|c|}{ MB root of the second molar } \\
\hline Malay & $\begin{array}{c}6.07 \pm 4.69 \mathrm{~mm} \\
(4.59 \text { to } 7.55)\end{array}$ & $\begin{array}{c}4.41 \pm 4.26 \mathrm{~mm} \\
(3.07 \text { to } 5.76)\end{array}$ & $\begin{array}{c}2.90 \pm 2.88 \mathrm{~mm} \\
(1.90 \text { to } 3.91)\end{array}$ & $\begin{array}{c}2.58 \pm 1.41 \mathrm{~mm} \\
(1.63 \text { to } 3.53)\end{array}$ \\
\hline Chinese & $\begin{array}{c}6.03 \pm 5.60 \mathrm{~mm} \\
(4.16 \text { to } 7.90)\end{array}$ & $\begin{array}{c}4.25 \pm 4.59 \mathrm{~mm} \\
(2.71 \text { to } 5.78)\end{array}$ & $\begin{array}{c}2.11 \pm 0.95 \mathrm{~mm} \\
(1.77 \text { to } 2.44)\end{array}$ & $\begin{array}{c}2.24 \pm 1.15 \mathrm{~mm} \\
(1.60 \text { to } 2.88)\end{array}$ \\
\hline Indian & $\begin{array}{c}5.93 \pm 3.67 \mathrm{~mm} \\
(4.58 \text { to } 7.27)\end{array}$ & $\begin{array}{c}4.12 \pm 2.88 \mathrm{~mm} \\
(3.06 \text { to } 5.17)\end{array}$ & $\begin{array}{c}3.39 \pm 1.81 \mathrm{~mm} \\
(2.57 \text { to } 4.21)\end{array}$ & $\begin{array}{l}2.60 \pm 0.85 \mathrm{~mm} \\
(-5.02 \text { to } 10.22)\end{array}$ \\
\hline \multicolumn{5}{|c|}{ DB root of the second molar } \\
\hline Malay & $\begin{array}{c}4.06 \pm 3.82 \mathrm{~mm} \\
(2.85 \text { to } 5.26)\end{array}$ & $\begin{array}{c}2.96 \pm 2.36 \mathrm{~mm} \\
(2.22 \text { to } 3.70)\end{array}$ & $\begin{array}{c}2.37 \pm 1.31 \mathrm{~mm} \\
(1.89 \text { to } 2.86)\end{array}$ & $\begin{array}{c}2.92 \pm 1.26 \mathrm{~mm} \\
(2.02 \text { to } 3.82)\end{array}$ \\
\hline Chinese & $\begin{array}{c}3.26 \pm 2.52 \mathrm{~mm} \\
(2.42 \text { to } 4.10)\end{array}$ & $\begin{array}{c}2.39 \pm 1.92 \mathrm{~mm} \\
(1.75 \text { to } 3.04)\end{array}$ & $\begin{array}{c}2.22 \pm 1.23 \mathrm{~mm} \\
(1.79 \text { to } 2.65)\end{array}$ & $\begin{array}{c}1.91 \pm 0.97 \mathrm{~mm} \\
(1.34 \text { to } 2.47)\end{array}$ \\
\hline Indian & $\begin{array}{c}4.35 \pm 3.85 \mathrm{~mm} \\
(2.93 \text { to } 5.76)\end{array}$ & $\begin{array}{c}3.94 \pm 4.18 \mathrm{~mm} \\
(2.41 \text { to } 5.48)\end{array}$ & $\begin{array}{c}2.72 \pm 1.33 \mathrm{~mm} \\
(2.13 \text { to } 3.31)\end{array}$ & $\begin{array}{l}3.80 \pm 0.85 \mathrm{~mm} \\
(-3.82 \text { to } 11.42)\end{array}$ \\
\hline \multicolumn{5}{|l|}{ Overall } \\
\hline Malay & $\begin{array}{c}7.13 \pm 4.50 \mathrm{~mm} \\
(6.57 \text { to } 7.69)\end{array}$ & $\begin{array}{c}5.30 \pm 3.67 \mathrm{~mm} \\
(4.84 \text { to } 5.78)\end{array}$ & $\begin{array}{c}3.39 \pm 2.20 \mathrm{~mm} \\
(3.06 \text { to } 3.72)\end{array}$ & $\begin{array}{c}3.02 \pm 1.50 \mathrm{~mm} \\
(2.54 \text { to } 3.50)\end{array}$ \\
\hline Chinese & $\begin{array}{c}7.52 \pm 5.11 \mathrm{~mm} \\
(6.87 \text { to } 8.17)\end{array}$ & $\begin{array}{c}5.65 \pm 4.20 \mathrm{~mm} \\
(5.10 \text { to } 6.20)\end{array}$ & $\begin{array}{c}3.10 \pm 1.76 \mathrm{~mm} \\
(2.85 \text { to } 3.36)\end{array}$ & $\begin{array}{c}2.61 \pm 1.55 \mathrm{~mm} \\
(2.21 \text { to } 3.00)\end{array}$ \\
\hline Indian & $\begin{array}{c}6.66 \pm 4.20 \mathrm{~mm} \\
(6.05 \text { to } 7.08)\end{array}$ & $\begin{array}{c}4.79 \pm 3.49 \mathrm{~mm} \\
(4.24 \text { to } 5.33)\end{array}$ & $\begin{array}{c}3.42 \pm 1.52 \mathrm{~mm} \\
(3.11 \text { to } 3.74)\end{array}$ & $\begin{array}{c}3.60 \pm 1.01 \mathrm{~mm} \\
(2.54 \text { to } 4.66)\end{array}$ \\
\hline
\end{tabular}

*Significant difference between Chinese and Indian. ANOVA post hoc Tukey test, $\mathrm{p}<0.05$. 
premolar regions was $4.83 \pm 2.55 \mathrm{~mm}, 5.19 \pm 3.36$ and $6.49 \pm 3.96 \mathrm{~mm}$, respectively. This shows that an increment in bone thickness occurs from the anterior region to the cuspid region. The thickness of the buccal wall further increased to $6.42 \pm 3.64 \mathrm{~mm}$ and $6.75 \pm 4.93 \mathrm{~mm}$ at the mesiobuccal (MB) and distobuccal (DB) roots, respectively, of the first molar. Following this, the thickness of the wall decreased; at the MB $(4.27 \pm 3.96 \mathrm{~mm})$ and $\mathrm{DB}(3.10 \pm 2.75 \mathrm{~mm})$ roots of the second molar, it was similar to that observed at the canine region.

When viewed at different levels, the mean bone thickness decreased with progression from the $10 \mathrm{~mm}$ level to $40 \mathrm{~mm}$ below the orbital floor (Table 1). The overall average bone thickness decreased from $7.14 \pm 4.66 \mathrm{~mm}$ at $\mathrm{H} 10$ to $2.82 \pm 1.52 \mathrm{~mm}$ at $\mathrm{H} 40$. The thickness at $\mathrm{H} 20$ and H30 fell between these 2 reported thickness, being $5.29 \pm 3.84 \mathrm{~mm}$ at $\mathrm{H} 20$ and $3.28 \pm 1.90 \mathrm{~mm}$ at $\mathrm{H} 30$. Figure 3 shows an example of the measurements obtained at the DB of the first molar.

Figure 4 shows in more detail the actual mean bone thickness observed at various levels and sites. Two distinct patterns can be observed. At the higher level of the sinus, the thickness at H10 and H20 increased gradually from the canine towards the first molar regions, only to decrease again at the second molar region. However, in no case was the average bone thickness less than $2.5 \mathrm{~mm}$. At the lower level of the sinus (H30 \& H40) (Figure 5), the lateral wall was thicker at the canine and premolar regions, but

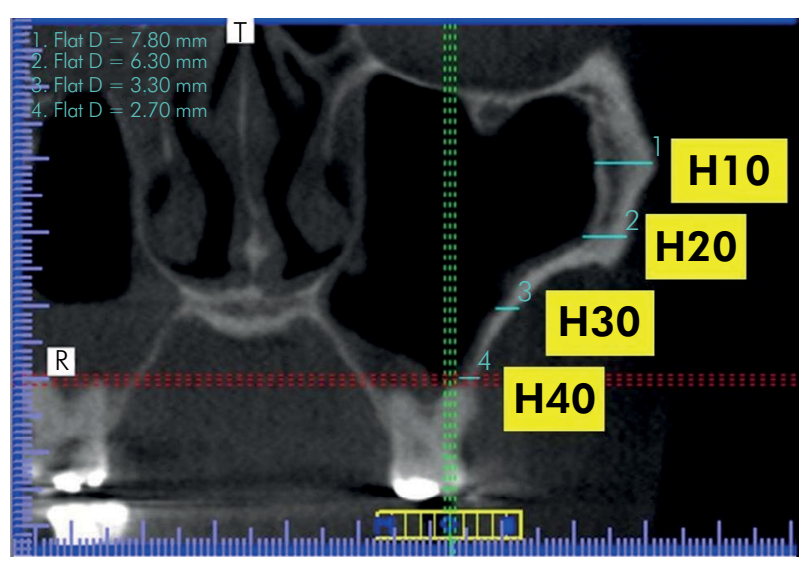

Figure 3. A typical coronal view of the sites of measurement. it decreased in thickness beginning at the first molar and continuing to the second molar region. At H30, the mean bone thickness at the second molar was approximately $2.5 \mathrm{~mm}$, but at $\mathrm{H} 40$, the mean bone thickness at the first and second molar regions was only slightly more than $2.0 \mathrm{~mm}$.

In general, it was observed that male patients presented thicker maxillary sinus walls than females (Table 1). Only at 4 reference points of measurement,

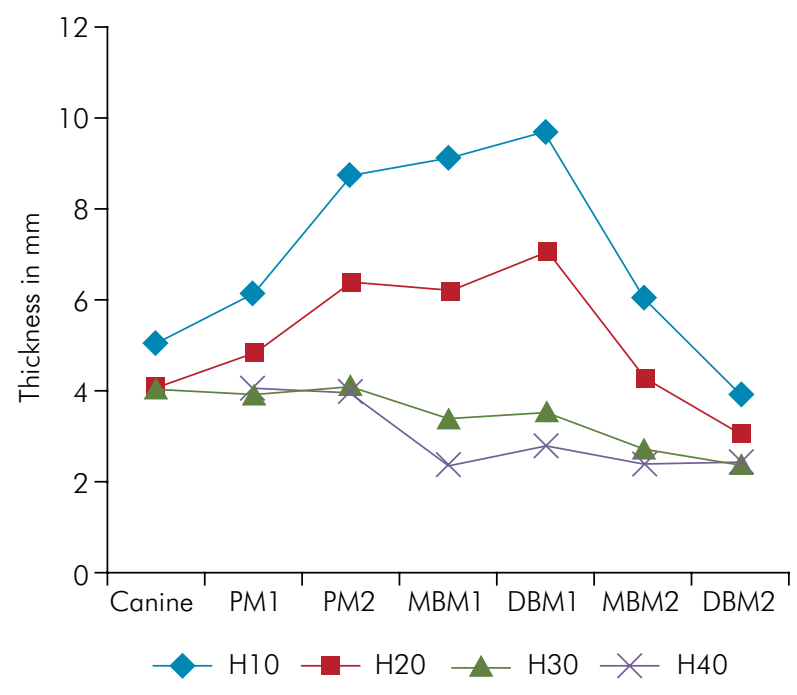

Figure 4. Line chart showing the distribution of lateral wall thickness at the intersection points between $\mathrm{H} 10, \mathrm{H} 2 \mathrm{O}, \mathrm{H} 30$ and $\mathrm{H} 40$ and the axis of the canine, first premolar (PM1), second premolar (PM2), mesiobuccal \& distobuccal roots of the first molar (MBM1 \& DBM1) and mesiobuccal \& distobuccal roots of the second molar (MBM2 \& DBM2). Two distinct patterns can be observed, those at $\mathrm{H} 10 / \mathrm{H} 20$ and those at $\mathrm{H} 30 / \mathrm{H} 40$.

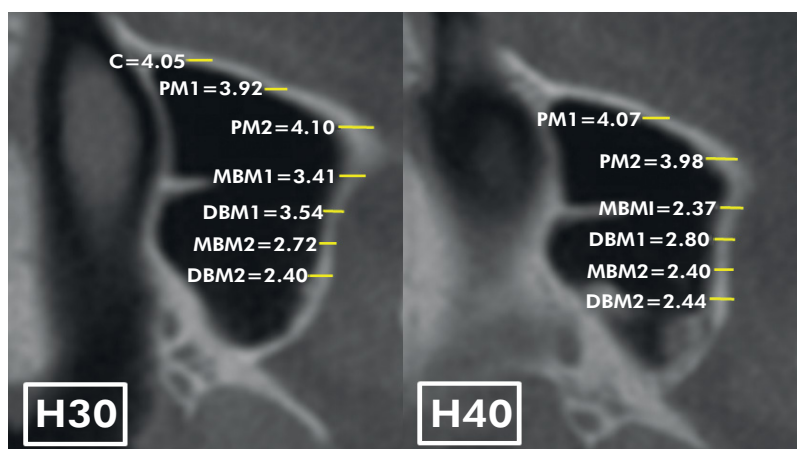

C: Canine; PM1: First premolar; PM2: Second premolar; M1: First molar; M2: Second molar; MB: Mesiobuccal root; DB: Distobuccal root.

Figure 5. Average thickness (in millimeters) of the buccofacial sinus wall at $\mathrm{H} 30$ and $\mathrm{H} 40$ in axial view. 
namely, at $\mathrm{H} 10$ and $\mathrm{H} 20$ of PM1 and of the MB root of the first molar, were the buccofacial walls thicker in female patients. However, none of the differences in bone thickness between the genders were statistically significant (independent $t$-test; $\mathrm{p}>0.05$ ).

The patients were subdivided into four groups according to age (1-20 years, 21-40 years, 41-60 years and greater than 61 years) as a basis for determining whether age affects the thickness of the buccofacial wall of the maxillary sinus. ANOVA showed that age did not affect the thickness of the buccofacial wall at any site or levels ( $p>0.05)$.

There were significant differences in bone thickness at the first molar region that depended on the ethnicity of the patients. This difference is seen at $\mathrm{H} 10$ of the MB and $\mathrm{DB}$ roots and at $\mathrm{H} 20$ of the DB root; in these locations, the mean bone thickness in Chinese patients was significantly greater than that in Indian patients (Table 2).

\section{Discussion}

Dentists usually encroach into the maxillary sinus on two occasions, namely, to retrieve a fractured root or to perform sinus augmentation (sinus lift) to overcome the lack of vertical height to allow implant fixture placement in the posterior maxillary region. The buccofacial wall of the maxillary sinus has been reported to be a thin bone plate that is easily penetrated by any rotating or sharp instrument such as a surgical rotating drill or saw, ${ }^{1}$ allowing these procedures to be performed easily. Although the Schneiderian membrane may possibly be breached when retrieving a fractured root, it should remain intact for sinus augmentation. An intact Schneiderian membrane, which usually averages approximately 1 $\mathrm{mm}$ in thickness, plays a crucial role in containing the inserted bone graft. ${ }^{20}$ It should be kept intact to avoid the loss of graft material and to provide coverage that offers vascular function.

The surgical procedure of preparing the trap door and luxating it, together with the elevation of the Schneiderian membrane, may cause the thin lining of the membrane to tear. ${ }^{1}$ It has been reported that Schneiderian membrane perforation remains the most common complication of sinus augmentation ${ }^{21}$ and that one of the factors contributing to this is the thickness of the lateral sinus wall. ${ }^{12}$ Perforations may also occur due to irregularities in the sinus wall that range from shallow ridges to crescent-shaped projections and septa of considerable size..$^{22,23,24}$ These irregularities have been shown to increase the risk of Schneiderian membrane perforation if a surgical procedure to gain access to the sinus chamber is undertaken. Another cause of Schneiderian membrane perforation is the presence of immediate contact between this membrane and the oral mucosa.

The thickness of the buccofacial maxillary sinus wall appears to influence the integrity of the Schneiderian membrane. ${ }^{1,12} \mathrm{~A}$ simple procedure such as osteotomy of the buccofacial wall may tear the Schneiderian membrane if too much pressure is exerted on the thin wall. ${ }^{12,25}$ Therefore, to successfully perform sinus bone augmentation via the lateral window approach, it is important for dentists to possess in-depth understanding of the anatomy of the maxillary sinus walls. In addition to the practitioner's sound basic knowledge, preoperative assessment of anatomical variations by radiographic evaluation is essential.

Today, cone-beam computed tomography (CBCT) can be used to evaluate anatomical variations of the maxillary sinus. ${ }^{26}$ In contrast to CT imaging, CBCT generates high-resolution isotropic volumetric data with high geometric accuracy at a low effective radiation dose that is only slightly greater than that used in panoramic radiography. ${ }^{27} \mathrm{CBCT}$ offers a reliable three-dimensional diagnostic image, unlike the 2-dimensional dentopantomograph and occipitomental views provided by conventional radiography.

The study of the buccofacial walls of the maxillary sinus can be undertaken directly on skulls/cadavers or on images obtained by CT or CBCT radiography. Few studies have used skulls or cadavers to study the thickness of the buccofacial wall of the maxillary sinus. Neiva et al., ${ }^{16}$ who did so using skulls, measured the thickness of the buccofacial wall of the maxillary sinus using a Boley gauge caliper in four locations (mesial, distal, apical and coronal) and reported that the mean thickness of the lateral wall of the maxillary sinus was $0.91 \pm 0.43 \mathrm{~mm}$ (range $0.5-2.0 \mathrm{~mm}$ ). In a study of 74 Korean hemiface cadavers, Yang et al. ${ }^{13}$ removed the lateral sinus wall to measure the buccofacial wall 
at various marked points using a bone depth gauge. They reported thicker bone that ranged in thickness from $1.23 \mathrm{~mm}$ to $1.86 \mathrm{~mm}$ at different points.

We chose to perform this study by studying CBCT scans of selected Asian patients because various studies have shown that measurements obtained from $\mathrm{CBCT}$ images are comparable to direct cadaveric measurements. ${ }^{28,29,30} \mathrm{CBCT}$ scans are preferred because they are more convenient and simpler from ethical, economical and technical points of view. The use of this approach circumvents the need to dissect Malay cadavers, which is a practical issue because they are impossible to obtain due to religious practice. ${ }^{31}$ Malay, Indian and Chinese patients were included in this study because they represent a majority of the Asian population (Malay: Indonesia \& Malaysia, 250 million; Indian: India, 1.2 billion; Chinese: China, 1.33 billion).

All previous studies used the floor of the sinus as the base point of reference. $12,13,14,15,16,17,18,19$. Because of the different landmarks used (axis of the teeth or the interdental region versus different distances from the floor of the sinus), these studies reported vastly different findings. In addition, all of these studies used the floor of the maxillary sinus as the main reference point despite the fact that it is generally acknowledged that alveolar ridge resorption proceeds at an average of $0.5-1.0 \%$ per year for the entire life of the patient following the loss of a tooth. ${ }^{32}$ Because of this process and due to pneumatization, the position of the floor of the sinus may change with time. Hence, the reference points of these studies were not consistent because some of the areas of study were edentulous and varied according to the different rates of alveolar bone resorption among individuals. We therefore decided to use the floor of the orbit as a reference point because, unlike the alveolar ridge, it is stable and does not undergo resorption.

It has been suggested that the maxillary sinus generally extends anterior to the canine premolar region. ${ }^{1}$ Contrary to this generally held belief, the current study found few canine regions that showed this extension of the maxillary sinus. As reported earlier, only slightly less than $40 \%$ of canines showed this extension. There seems to be racial variation in this presentation; canine extension was observed more often in Chinese patients than in Malay and
Indian patients. In contrast, in a high proportion of patients (80\%), the maxillary sinus extended to the first premolar region, and the racial distribution of this trait was similar to that of the extension at the canine region. These features are not only useful in the field of oral surgery and implantology but may also have a role in the field of forensic medicine for ethnic identification, an area that warrants future study.

Overall, the mean thickness of the buccofacial maxillary sinus wall at every point of measurement in our patients was found to be more than $2.0 \mathrm{~mm}$. In general, this is higher than the values that have been reported for Caucasians and Koreans. ${ }^{14,16,19}$ Only 2 other studies reported observing a thickness of more than $2 \mathrm{~mm} \cdot{ }^{12,18} \mathrm{Li}$ et al. ${ }^{12}$ reported a thickness of $2.23 \mathrm{~mm}$ at the second premolar and a thickness of $2.19 \mathrm{~mm}$ at the first molar region $5 \mathrm{~mm}$ from the floor of the sinus in Han Chinese. Comparatively, the measurements observed in the current study (Table 2) are considerably higher, assuming the $\mathrm{H} 40$ level to be the closest to Li et al's level of measurement.

The points used by Monje et al. ${ }^{15}$ in measuring the CBCT images of 140 patients were the intersections of the axis of the second premolar, the first molar and the second molar with lines $3 \mathrm{~mm}, 5 \mathrm{~mm}, 7 \mathrm{~mm}$, $10 \mathrm{~mm}, 13 \mathrm{~mm}$ and $15 \mathrm{~mm}$ from the lowest point of the sinus floor. In addition, their patients presented either with complete edentulous atrophic maxilla (CEM) or partial edentulous atrophic maxilla (PEM). These investigators showed that the type of edentulism (PEM or CEM) impacts lateral wall thickness. Nevertheless, in their studies of Han Chinese, Li et al..$^{12}$ failed to find any effect of edentulism on the thickness of the buccofacial wall of the maxillary sinus. Instead, they found that gender was a confounding factor.

In contrast to the findings of $\mathrm{Li}$ et $\mathrm{al}^{12}$ and in agreement with several previous studies, ${ }^{15,19,32,33,34}$ this study found that gender does not affect the thickness of the buccofacial maxillary sinus wall. The authors also found that the age of the patients was not a confounding factor affecting the thickness of the buccofacial maxillary sinus wall, again in contrast to the results reported by Li et al. ${ }^{12}$ and Monje et al. ${ }^{15}$ Monje et al. ${ }^{15}$ reported that maxillary sinus wall thickness was directly proportional to patient age, 
whereas Li et al. ${ }^{12}$ found an influence of age in the region of the molars.

Two studies found that buccofacial wall thickness tended to increase from the region of the second premolar to that of the second molar. ${ }^{14,15}$ In contrast, in a study of 74 non-embalmed Korean hemifaces, Yang et al. ${ }^{13}$ reported that the buccofacial wall was thinner in the second molar region than in the first molar region, in agreement with the current findings. A similar observation was recently reported by Danesh-Sani et al. ${ }^{19}$ Surprisingly, Li et al. ${ }^{12}$ found that the buccofacial wall gradually became thinner from the region of the second premolar towards the region of the second molar, $5 \mathrm{~mm}$ from the floor of the sinus. This observation is consistent with our findings for all 3 ethnic groups in this study.

The 2 main clinical implications of this study are as follows:

At $\mathrm{H} 30$ and $\mathrm{H} 40$, surgical access for sinus augmentation requires considerable patience and the application of less pressure in the premolar region, whereas in the first molar region, deeper drilling is necessary because the buccofacial wall increases in thickness in this area. This extra-thick area of bone may require thinning to make it easier to free the Schneiderian membrane from the inner wall of the sinus in this region..$^{1,12}$

Because the lateral wall of the first molar area is thick at $\mathrm{H} 10$ and $\mathrm{H} 20$, this region can become a source of donor material for the bone graft. Bone can

\section{References}

1. Bergh JP, Bruggenkate CM, Disch FJ, Tuinzing

DB. Anatomical aspects of sinus floor elevations.

Clin Oral Implants Res. 2000;11(3):256-65.

https://doi.org/10.1034/j.1600-0501.2000.011003256.x

2. Vogel R, Smith-Palmer J, Valentine W. Evaluating the health economic implications and cost-effectiveness of dental implants: a literature review. Int J Oral Maxillofac Implants. 2013;28(2):343-56. https://doi.org/10.11607/jomi.2921

3. Chanavaz M. Maxillary sinus: anatomy, physiology, surgery, and bone grafting related to implantology: eleven years of surgical experience (1979-1990). J Oral Implantol. 1990;16(3):199-209.

4. Cawood JI, Howell RA. A classification of the edentulous jaws. Int J Oral Maxillofac Surg. 1988 Aug;17(4):232-6. https://doi.org/10.1016/S0901-5027(88)80047-X be harvested from this region using a bone scraper. Using this site as a source of autologous bone graft material is of great clinical benefit, especially during a sinus elevation procedure, because it eliminates the necessity to expose a distant donor site.

In this study, despite our best attempts to measure the buccofacial wall of the maxillary sinus in a direction as perpendicular as possible to the long axis of the roots, the measurements obtained in the area of the canine root may not be ideal as a result of the curvature of the maxillary arch at the canine region and of the angulation of the root of the canine.

\section{Conclusion}

In summary, the buccofacial wall of the maxillary sinus becomes thicker anteroposteriorly, except in the region of the second molar, and thinner superoinferiorly. The findings of the current study confirm previous observations that the thickness of the lateral wall of the maxillary sinus is not well distributed. This may influence the approach to performing the clinical procedures listed in the Introduction section of this paper.

\section{Acknowledgment}

This work was supported by the University of Malaya's High Impact Research grant UM.C/625/1/ HIR/MOHE/05.
5. Vinter I, Krmpotić-Nemanić J, Hat J, Jalsovec D. [Does the alveolar process of the maxilla always disappear after tooth loss?]. Laryngorhinootologie. 1993;72(12):605-7. German. https://doi.org/10.1055/s-2007-997963

6. Underwood AS. An inquiry into the anatomy and pathology of the maxillary sinus. J Anat Physiol. 1910;44(Pt 4):354-69.

7. Boyne PJ, James RA. Grafting of the maxillary sinus floor with autogenous marrow and bone. J Oral Surg. 1980;38(8):613-6.

8. Tatum H Jr. Maxillary and sinus implant reconstructions. Dent Clin North Am. 1986;30(2):207-29.

9. Summers RB, Mawr B, Einstein A. The osteotome technique: Part 3: Less invasive methods of elevating the sinus floor. Compendium. 1994;15(6):698-708. 
The implications of different lateral wall thicknesses on surgical access to the maxillary sinus

10. McAllister BS, Haghighat K. Bone augmentation techniques. J Periodontol. 2007;78(3):377-96. https://doi.org/10.1902/jop.2007.060048

11. Palma VC, Magro-Filho O, Oliveria JA, Lundgren S, Salata LA, Sennerby L. Bone reformation and implant integration following maxillary sinus membrane elevation: an experimental study in primates. Clin Implant Dent Relat Res. 2006;8(1):11-24. https://doi.org/10.2310/i.6480.2005.00026.x

12. Li J, Zhou ZX, Yuan H, Shen M, Sun C, Chen N. [A study of maxillary sinus lateral wall thickness of Han population in Jiangsu region using cone-beam CT]. Shanghai Kou Qiang Yi Xue. 2013;22(5):537-41. Chinese.

13. Yang HM, Bae HE, Won SY, Hu KS, Song WC, Paik DJ et al. The buccofacial wall of maxillary sinus: an anatomical consideration for sinus augmentation. Clin Implant Dent Relat Res. 2009;11 Suppl 1:e2-6. https://doi.org/10.1111/j.1708-8208.2009.00138.x

14. Yang SM, Park SI, Kye SB, Shin SY. Computed tomographic assessment of maxillary sinus wall thickness in edentulous patients. J Oral Rehabil. 2012;39(6):421-8. https://doi.org/10.1111/j.1365-2842.2012.02295.x

15. Monje A, Catena A, Monje F, Gonzalez-García R, Galindo-Moreno P, Suarez F et al. Maxillary sinus lateral wall thickness and morphologic patterns in the atrophic posterior maxilla. J Periodontol. 2014;85(5):676-82. https://doi.org/10.1902/jop.2013.130392

16. Neiva RF, Gapski R, Wang HL. Morphometric analysis of implant-related anatomy in Caucasian skulls. J Periodontol. 2004;75(8):1061-7. https://doi.org/10.1902/jop.2004.75.8.1061

17. Kang SJ, Shin SI, Herr Y, Kwon YH, Kim GT, Chung JH. Anatomical structures in the maxillary sinus related to lateral sinus elevation: a cone beam computed tomographic analysis. Clin Oral Implants Res. 2013;24 Suppl A100:75-81. https://doi.org/10.1111/j.1600-0501.2011.02378.x

18. Khajehahmadi S, Rahpeyma A, Hoseini Zarch SH. Association between the lateral wall thickness of the maxillary sinus and the dental status: cone beam computed tomography evaluation. Iran J Radiol. 2014;11(1):e6675. https://doi.org/10.5812/iranjradiol.6675

19. Danesh-Sani SA, Movahed A, ElChaar ES, Chong Chan K, Amintavakoli N. Radiographic evaluation of maxillary sinus lateral wall and posterior superior alveolar artery anatomy: a cone-beam computed tomographic study. Clin Implant Dent Relat Res. 2017;19(1):151-60. https://doi.org/10.1111/cid.12426

20. Monje A, Diaz KT, Aranda L, Insua A, Garcia-Nogales A, Wang HL. Schneiderian membrane thickness and clinical implications for sinus augmentation: A systematic review and meta-regression analyses. J Periodontol. 2016;87(8):888-99. https://doi.org/10.1902/jop.2016.160041

21. Pjetursson BE, Tan WC, Zwahlen M, Lang NP. A systematic review of the success of sinus floor elevation and survival of implants inserted in combination with sinus floor elevation. J Clin Periodontol. 2008;35(8 Suppl):216-40. https://doi.org/10.1111/j.1600-051X.2008.01272.x
22. McGowan DA, Baxter PW, James J. The maxillary sinus and its dental implications. Oxford: Wright, Butterworth-Heinemann; 1993.

23. Chan HL, Monje A, Suarez F, Benavides E, Wang HL. Palatonasal recess on medial wall of the maxillary sinus and clinical implications for sinus augmentation via lateral window approach. J Periodontol. 2013;84(8):1087-93. https://doi.org/10.1902/jop.2012.120371

24. Chan HL, Wang HL. Sinus pathology and anatomy in relation to complications in lateral window sinus augmentation. Implant Dent. 2011;20(6):406-12. https://doi.org/10.1097/ID.0b013e3182341f79

25. Hernández-Alfaro F, Torradeflot MM, Marti C. Prevalence and management of Schneiderian membrane perforations during sinus-lift procedures. Clin Oral Implants Res. 2008;19(1):91-8. https://doi.org/10.1111/j.1600-0501.2007.01372.x

26. Kumar V. Applications of Cone Beam Computed Tomography (CBCT) in implant treatment planning. JSM Dent. 2013;1(2):1008.

27. Mah JK, Danforth RA, Bumann A, Hatcher D. Radiation absorbed in maxillofacial imaging with a new dental computed tomography device. Oral Surg Oral Med Oral Pathol Oral Radiol Endod. 2003;96(4):508-13. https://doi.org/10.1016/S1079-2104(03)00350-0

28. Doran D, Hollender L, Peck J, Girod S. Direct digital panoramic radiology and 2-D reconstructions of cone beam computed tomography in localization of the inferior alveolar canal and maxillary floor of sinus for intraosseous dental implants. J Oral Maxillofac Surg. 2004;62(Suppl 1):S37-8. https://doi.org/10.1016/i.joms.2004.05.169

29. Kamburoğlu K, Kiliç C, Özen T, Yüksel SP. Measurements of mandibular canal region obtained by cone-beam computed tomography: a cadaveric study. Oral Surg Oral Med Oral Pathol Oral Radiol Endod. 2009;107(2):e34-42. https://doi.org/10.1016/j.tripleo.2008.10.012

30. Kamburoğlu K, Kolsuz E, Kurt H, Kiliç C, Özen T, Paksoy CS. Accuracy of CBCT measurements of a human skull. J Digit Imaging. 2011;24(5):787-93. https://doi.org/10.1007/s10278-010-9339-9

31. Al-Siweedi SY, Nambiar P, Shanmuhasuntharam P, Ngeow WC. Gaining surgical access for repositioning the inferior alveolar neurovascular bundle. Sci World J. 2014;2014:719243. https://doi.org/10.1155/2014/719243

32. Pagni G, Pellegrini G, Giannobile WV, Rasperini G. Postextraction alveolar ridge preservation: biological basis and treatments. Int J Dent. 2012;2012:151030. https://doi.org/10.1155/2012/151030

33. Güler AU, Sumer M, Sumer P, Biçer I. The evaluation of vertical heights of maxillary and mandibular bones and the location of anatomic landmarks in panoramic radiographs of edentulous patients for implant dentistry. J Oral Rehabil. 2005;32(10):741-6. https://doi.org/10.1111/j.1365-2842.2005.01499.x

34. Neugebauer J, Ritter L, Mischkowski RA, Dreiseidler T, Scherer $\mathrm{P}$, Ketterle $\mathrm{M}$ et al. Evaluation of maxillary sinus anatomy by cone-beam CT prior to sinus floor elevation. Int J Oral Maxillofac Implants. 2010;25(2):258-65. 